\title{
Multiple Colonic Radiopaque Foreign Bodies in a 7-Year-Old Child: The Plain Radiographic Features and a Case Report
}

\author{
Sule MB ${ }^{1}$, Gele $\mathbf{I H}^{2}$, Shirama $\mathbf{Y B}^{2}$, Ribah $\mathbf{M M}^{2}$, Aliyu $\mathrm{AZ}^{2}$, Abacha $\mathbf{M}^{3}$ \\ ${ }^{1}$ Department of Radiology, Usmanu Danfodiyo University, Sokoto. \\ ${ }^{2}$ Department of Radiology, Usmanu Danfodiyo University Teaching Hospital, Sokoto. \\ ${ }^{3}$ Department of Radiography, Usmanu Danfodiyo University, Sokoto.
}

*Corresponding Author: Sule MB, Department of Radiology, Usmanu Danfodiyo University, Sokoto.

Received date: June 10, 2021 Accepted date: June 12, 2021 Published date: July 24, 2021

Citation: Sule MB, Gele IH, Shirama YB, Ribah MM, Aliyu AZ, Abacha M (2021) Multiple Colonic Radiopaque Foreign Bodies in a 7-Year-Old Child: The Plain Radiographic Features and A Case Report. J. Gastroenterology Pancreatology and Hepatobilary Disorders. 5(4) DOI: 10.31579/2641$5194 / 039$

Copyright: (C) 2021, Sule MB, This is an open access article distributed under the Creative Commons Attribution License, which permits unrestricted use, distribution, and reproduction in any medium, provided the original work is properly cited.

\begin{abstract}
Foreign bodies are uncommon and may be ingested, inserted into a body cavity or deposited in the body by traumatic or iatrogenic injury.

Foreign body ingestion is more common in children with equal incidence in males and females, and has a peak incidence in the ages between six months to three years.

This is a case of a seven-year-old male child with behavioral abnormality and long history of ingestion of foreign bodies who presented with abdominal pain and discomfort with passage of hard solid stone like particles in feaces.

The patient had a conventional abdominal radiograph that showed multiple radiopaque structures of varying sizes, some of which are clump-like in the peripheral abdomen; the large colon and region of the rectum.

Keywords: foreign, multiple, bodies, radiopaque.
\end{abstract}

\section{Introduction}

Foreign body ingestion is a potentially serious problem that peaks in children aged between six months to three years, has a morbidity of less than one percent and causes about 1500 deaths annually in the united states [1-3].

Most foreign bodies (FB) in the gastrointestinal tract pass spontaneously without complications, some may require either endoscopic or surgical removal in a few children $[3,4]$.

Children and mentally ill patients commonly swallow foreign bodies, and coins are the most common swallowed foreign body seeking medical attention in the USA [5-7].

The most commonly ingested FBs from the most to least common are coins, magnets, batteries, small toys, jewelry, buttons and bones [5, 8].

Because most FBs pass spontaneously, surgical removal is considered only if no radiographic progression is evident by 3 days following ingestion or if the patient becomes symptomatic $[9,10]$.
Imaging plays an important role in the diagnosis of ingested or aspirated foreign bodies in children and can be crucial in the clinical management of these group of patients [11].

The passage rate of ingested radiopaque FBs is $64.4 \%$, small FBs that have passed the duodenal curve should be managed conservatively via clinical observation and radiographic surveillance [12].

\section{Case Report}

This is a 7-year-old male child with abnormal behavior that was referred from a peripheral health care centre for abdominal radiograph on account of recurrent abdominal pain and discomfort, passage of hard altered colored substance from the anus and history of ingestion of different substances for a long period of time.

The patient subsequently had an abdominal radiograph that showed normal bowel gas pattern, no feature of intestinal obstruction and perforation. The radiograph showed multiple radiopaque materials of varying sizes in the region of the large bowel more in the region of the ascending colon and rectum. These radiopaque materials are either solitary or clump-like, most of which have a diameter of less than $3 \mathrm{~cm}$. 
We did a complementary abdominal ultrasound that showed normal abdominal organs but marked acoustic shadowing in the region of the large bowel was demonstrated.
We decided to report the radiographic findings of this case due to its peculiar and rare nature in our daily practice.

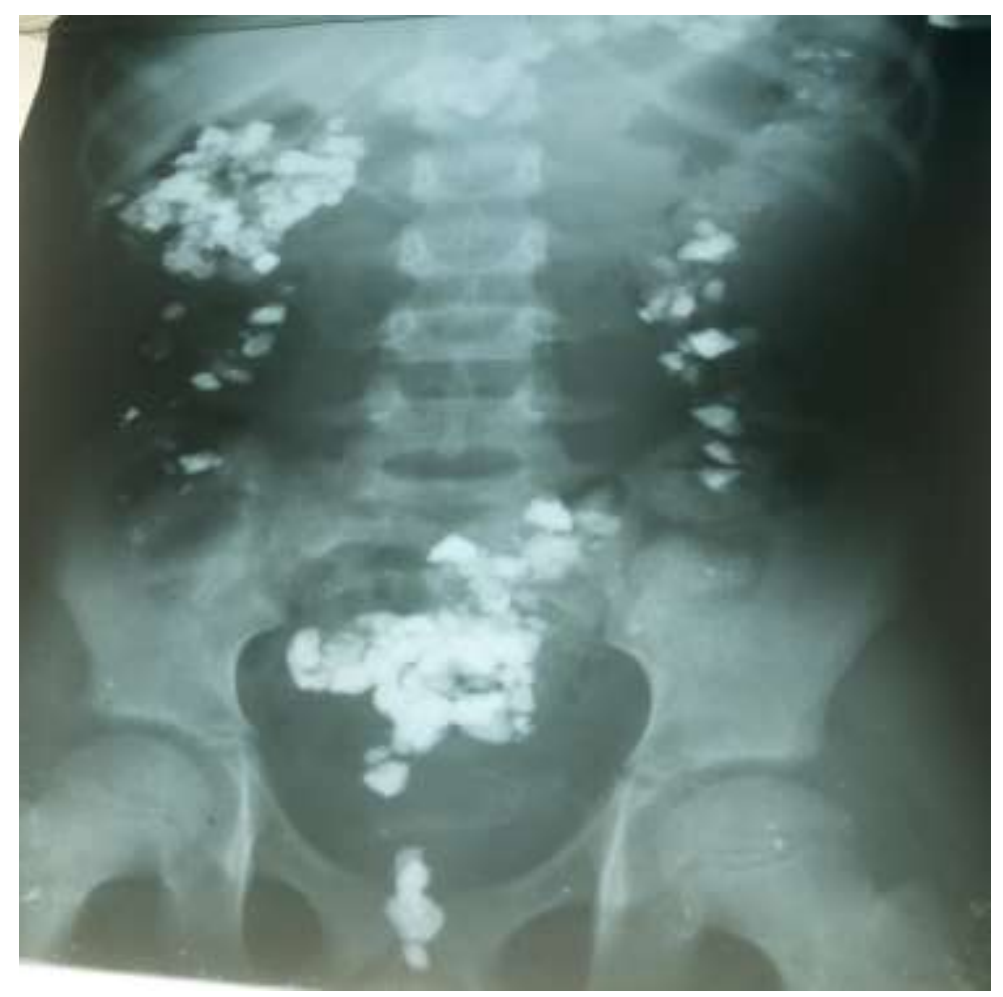

Figure 1: A plain abdominal radiograph of a child in a supine position showing multiple radiopacities in the region of the large bowel, these opacities are of varying sizes but appear clump like in the region of the ascending colon, transverse colon and recto-sigmoid colon. Normal bowel gas distribution and normal underlying bones were demonstrated. No feature of intestinal obstruction or perforation is demonstrated.

\section{Discussion}

Foreign bodies in the gastrointestinal tract are often encountered in children and mentally unstable patients; the index case is a child of seven years and happens to be mentally unstable.

No sex predilection is documented in most literatures, some literatures however believe that foreign body ingestion has a female preponderance; the index case is a male child contrary to the literatures with female preponderance.

The commonest presenting symptoms are abdominal pain and discomfort, abdominal distension, vomiting, and passage of hard materials from the anus. Most of these symptoms were found in the index case, however no feature of intestinal obstruction or perforation was documented in this case.

Imaging has played a role in the diagnosis of foreign bodies in the gastrointestinal tract as documented in the literature, this case is not an exception as the diagnosis was made from demonstration of radiopaque materials in the large bowel following abdominal radiography.

No radiopacities were demonstrated centrally or in the region of the small bowel and stomach most likely that they have passed successfully in to the large intestine; these might be because of the shape and size of the foreign bodies and the long history/period of ingestion by the patient. These reasons were those provided and documented in most literatures and might be responsible for not developing any form of intestinal obstruction by the patient.

\section{Conclusion}

Basic radiographic imaging like abdominal radiograph should be done for children with complaint of recurrent abdominal pain especially between the ages of six months to three years to rule out the possibility of foreign body in the gastrointestinal tract and to prevent complications that may be life threatening in these group of patients.

\section{References}

1. Monte CU. (2005). Foreign Body Ingestion in Chldren. Am Fam Physician. 72:287-291.

2. Chen MK, Beierle EA. (2001). Gastrointestinal foreign bodies. Pediatr Ann. 30:736-742.

3. Ji HK. (2018) Foreign Body Ingestion in Children. Clin Endosc. 51:129-136.

4. Conners GP, Mohseni M.(2019) Pediatric Fooreign Body Ingestion.

5. Jahsan F, Sela E, Layous E, Levy E, Assadi N, Shilo E, et al.(2018). Clinical criteria for CT scan evaluation of upper digestive tract fishbone. Laryngoscope.; 128:2467-2472.

6. Laya BF, Restrepo R, Lee EY.(2017) Practical Imaging Evaluation of Foreign Bodies in Children: An Update. Radiol Clin. North Am.; 55:845-867.

7. Kay M, Wyllie R.(2005) Pediatric foreign bodies and their management. Curr Gastroenterol Rep.; 7:212-218.

8. Hesham A-Kader H.(2010) Foreign body ingestion: children like to put objects in their mouth. World J Pediatr.; 6:301-310.

9. Rodriguez-hermosa JI, Codina-Cazador A, Sirvent JM, Martin A, Girones J, Garsot E. ( 2008). Surgically treated perforations 
of the gastrointestinal tract caused by ingested foreign bodies. Colorectal Dis.;10:701-707.

10. Brian SP, Ruth L, Laura LA. (2015) Review of Ingested and Aspirated Foreign Bodies in Children and Their Clinical Significance for Radiologist. RadioGraphics.; 35:140287.
11. Hung-Yu Y, Hsun-Chin C, Shih-Yen C, Chien-Chang C, MingWei L. (2018). Analysis of Radiopaque Gastrointestinal Foreign Bodies Expelled by Spontaneous Passage in Children: A 15-Year Single- Centre Study. Front Pediatr.; 6:172.
This work is licensed under Creative Commons Attribution 4.0 License

\section{To Submit Your Article Click Here: Submit Manuscript}

DOI: $10.31579 / 2641-5194 / 035$
Ready to submit your research? Choose Auctores and benefit from:

* fast, convenient online submission

* rigorous peer review by experienced research in your field

* rapid publication on acceptance

* authors retain copyrights

* unique DOI for all articles

* immediate, unrestricted online access

At Auctores, research is always in progress.

Learn more auctoresonline.org/journals/gastroenterology-pancreatologyand-hepatobilary-disorders 